\title{
INSTITUTO
}

\section{ASTRONÔMICO E GEOFÍSICO DA USP}

Contemplando as estrelas mas de olho no interior da Terra, o Instituto Astronômico e Geofísico (IAG) completou 50 anos de incorporação à Universidade de São Paulo. É uma longa história, desde sua origem, em 1886, com a Comissão Geográfica e Geológica do Estado de São Paulo, passando por denominações diferentes e por diversas secretarias de Estado. Só em 1972 o IAG foi transformado em Unidade de Ensino e Pesquisa, com a constituição dos departamentos de Astronomia, Geofísica e Meteorologia (atualmente Ciências Atmosféricas).

A primeira sede do Observatório Astronômico e Geofísico, inaugurada em 1912, foi na Av. Paulista. Em 1928, com o crescimento da cidade, o local tornou-se inadequado para observações astronômicas, devido ao aumento da luminosidade, e para observações sismográficas, por causa dos abalos produzidos pelos bondes que trafegavam pela Avenida.

O Instituto hoje está instalado em duas sedes, uma na Cidade Universitária, onde funcionam os cursos de graduação e pós-

\section{A AUTORA}

Márcia Furtado Ribeiro de Souza

Jornalista, pós-graduanda em Comunicação na ECA/USP e responsável pela divulgação científica (comunicação) do IAG-USP. graduação em Meteorologia e Geofísica e a outra no Parque do Estado, na Água Funda, onde funcionam o curso de pós-graduação em Astronomia, a Estação Meteorológica, a administração e serviços de apoio e o Observatório Astronômico, que não é mais utilizado para pesquisas por situar-se numa área urbana com muita luminosidade e poluição. O Observatório foi transferido para Valinhos e, atualmente, o telescópio principal do IAG está instalado no LNA Laboratório Nacional de Astrofísica do $\mathrm{CNPq}$, no Pico dos Neves, em Itajubá, Minas Gerais, local mais apropriado para observações.

Os três departamentos dedicam-se intensamente a atividades de pesquisa científica. O IAG é uma das unidades da USP com maior número de artigos publicados por docente em revistas científicas internacionais com arbitragem. Mas é o enorme interesse do público, por suas três áreas de atuação, que faz com que o Instituto se dedique, cada vez mais, às atividades de extensão.

O Departamento de Astronomia atende consultas diárias, por carta e telefone, sobre os mais diversos temas astronômicos. Um dos motivos é a lacuna existente nos livros escolares que, em geral, não suprem as necessidades dos estudantes nos temas ligados 


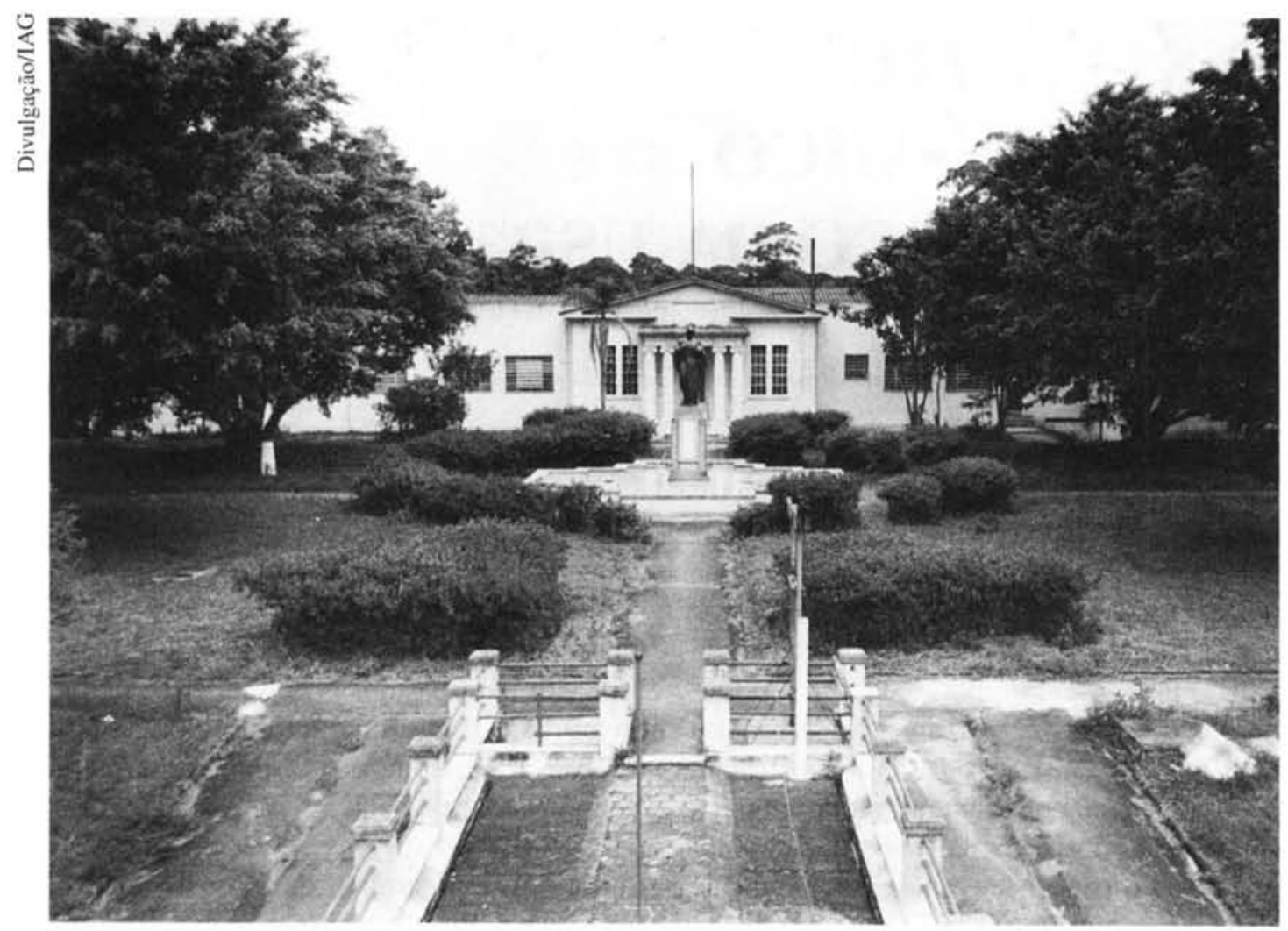

Vista da parte central do IAG - Água Funda

à Astronomia, constantes no currículo escolar. Como forma de contribuir com um conhecimento maior na área o Departamento promove, às quartas-feiras para escolas e às sexta-feiras para o público em geral, visitas compreendendo palestras sobre Astronomia seguidas de observação do céu noturno através de um telescópio refrator Zeiss de $180 \mathrm{~mm}$. As visitas são agendadas previamente por telefone e o programa tem lista de espera de várias semanas. A maior procura é feita por professores de segundo grau ou das sétimas e oitavas séries do primeiro grau, procurando complementar a formação de seus alunos. Atualmente, este programa está sendo remodelado, com a inclusão de recursos de informática e a instalação de um telescópio refletor mais moderno.

\section{SERVIÇOS À COMUNIDADE}

O Departamento de Geofísica tem uma forte atuação na parte de prestação de serviços a empresas particulares, estatais e prefeituras em áreas que incluem desde a pesquisa de recursos minerais, avaliação de poluição de aqüíferos, avaliação da segurança de obras e populações vizinhas, que podem ser afetadas pela indução de tremores de terra provocados por grandes obras de engenharia, até os estudos da sismicidade úteis para a segurança de comunidades situadas em regiões de ocorrência de abalos sísmicos. Mantém, ainda, um convênio com a Defesa Civil para a prestação de atendimento imediato em caso de ocorrência desses abalos. As atividades relacionadas à di- 


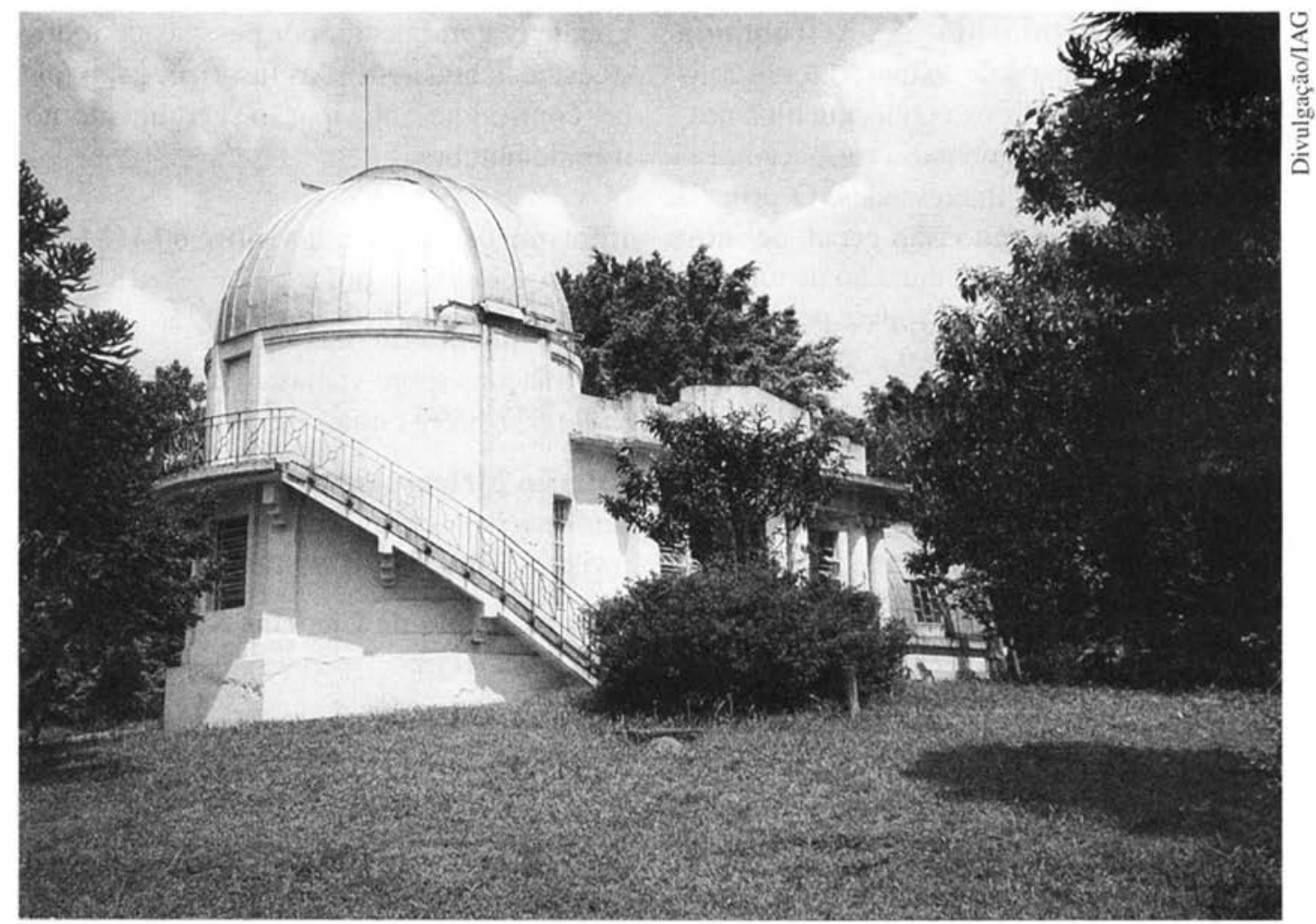

Cúpula Zeuss, Observatório Astronômico/ IAG, Água Funda.

vulgação incluem palestras realizadas pelos docentes em escolas de primeiro e segundo graus e cursos pré-vestibulares, promoção e participação em eventos científicos e culturais, além de atendimento a estudantes, imprensa e público em geral, para prestação de esclarecimentos e informações.

O Departamento de Ciências Atmosféricas recebe anualmente 1.500 alunos de primeiro e segundo graus, para visita à Estação Meteorológica.

O programa consta da apresentação de instrumental meteorológico instalado e do funcionamento regular da Estação, além de palestra e apresentação de material audiovisual com espaço para perguntas e respostas.
Atendendo um máximo de 40 crianças, duas vezes por semana, a visita é indicada para alunos que estejam cursando disciplinas em cujos programas constem assuntos diretamente relacionados com a Meteorologia, como é o caso da Geografia e das Ciências Físicas e Naturais. Os alunos devem ser acompanhados pelos professores que estejam ministrando essas disciplinas, para que o aproveitamento seja mais eficiente. Os docentes do Departamento apresentam palestras em escolas de primeiro e segundos graus ou em outras entidades que desenvolvam trabalhos vocacionais. A Estação fornece dados climatológicos para instituições públicas e privadas das mais diversas áreas, inclusive destinados a trabalhos de pesquisa, dissertações de mestrado e teses de doutoramento. 
O Departamento de Astronomia oferece dois cursos de extensão, com a finalidade de difundir os conhecimentos nessa área e de complementar a formação acadêmica de pessoas interessadas. O primeiro, Astronomia: uma visão geral, de caráter mais genérico e com duração de uma semana, tem como público alvo pessoas de formação superior em geral e, preferencialmente, professores de ensino médio. O curso Introdução à Astronomia e Astrofísica, com duração de duas semanas, é mais especializado, com um nível de detalhamento maior, exigindo conhecimentos de física e cálculo intregral e diferencial. É destinado a graduandos e pós-graduandos em áreas de Ciências Exatas. Os cursos são gratuitos e acontecem, todos os anos, no mês de janeiro. Como a procura é muito

Resumo: O Instituto Astronômico e Geofísico da USP completou cem anos em 1996 e, instalado em duas sedes (Cidade Universitária e Parque do Estado, na Água Funda), presta serviços a empresas, instituiçōes públicas e ao público em geral sobre temas ligados à astronomia, recursos minerais, poluição, sismicidade de solos, meteorologia e climatologia.

Palavras-chave: Instituto Astronômico e Geofisico, Astronomia, Geofísica, Meteorologia grande e, geralmente, por pessoas de todos os estados brasileiros, as inscrições são feitas com muita antecipação, geralmente no mês de outubro.

Informações detalhadas sobre o IAG-USP podem ser obtidas no:

\section{Departamento de Astronomia:}

Informações sobre visitas e cursos: (011) 577-8599 ramais 222 ou 223

\section{Estação Meteorológica:}

Informações sobre fornecimento de dados e visitas:(011) 577-8599 ramal 249

\section{Departamento de Ciências Atmosféricas: (011) 818-4713}

\section{Departamento de Geofísica: (011) 818-4755}

Abstract: The Institute of Astronomy and Geophysics of the University of São Paulo completed 100 years in 1996. Based on two different central premises (Cidade Universitária and Parque do Estado, in the Água Funda neighborhood), it is a service provider to business companies, public institutions and to the public in general in the fields of Astronomy, Mineral Resources, pollution, seismism, meteorology, and climatology.

Key-words: Institute of Astronomy and Geophysics, Astronomy, Geophysics, Meteorology 